\title{
Insulating Materials at Very Low Temperatures: A Short Review
}

\author{
Petros Malelis \\ Democritus University of Thrace \\ Department of Electrical and Computer Engineering \\ Power Systems Laboratory \\ Xanthi, Greece \\ petrmale@ee.duth.gr
}

\author{
Michael G. Danikas \\ Democritus University of Thrace \\ Department of Electrical and Computer Engineering \\ Power Systems Laboratory \\ Xanthi, Greece \\ mdanikas@ee.duth.gr
}

\begin{abstract}
In this paper, a short review is given on insulating materials at very low temperatures. Various insulating materials are investigated in terms of phenomena such as partial discharges. Some of the factors affecting the behavior of the insulating materials at very low temperatures, such as the quality of the electrode surface, the stressed insulation volume, and the existing bubbles, are also reported and commented upon. Proposals for future research are also discussed.
\end{abstract}

Keywords-superconductors; high temperature superconductors (HTS); cryogenic insulation; liquid nitrogen; partial discharges; streamers; aging of materials

\section{INTRODUCTION}

Since the discovery of superconduction in 1911, there were plans for the design of superconducting cables [1]. After several decades from this discovery, the development of superconducting cables seemed to be possible. Since the mideighties of the last century, there is a drastic development in superconducting research because of the discovery of high temperature superconductors (HTS) in the critical temperature $\mathrm{T}_{\mathrm{c}}>\mathrm{T}$ of liquid nitrogen $(77 \mathrm{~K})$ by Georg Bednorz and Karl Mueller of IBM, Rueschlikon, Switzerland. Let us notice that the power needed at room temperature for the function of a refrigerator at $77 \mathrm{~K}$ is lower than the one tenth of the power needed for the function of a refrigerator at $4 \mathrm{~K}$. Regarding superconductivity and its possible applications, it becomes apparent that electrical insulation is pivotal to the development of reliable energy systems. A breakdown of the electrical insulation may have catastrophic consequences for a superconducting energy system. A HTS superconducting cable offers reduced losses, it is more environment-friendly, it increases the reliability of the system and, it is more flexible than most traditional cables. There is a hope that HTS superconducting cables may give the solution for large urban centers in the future, as the global population increases and the demand for electricity becomes more acute. To be sure, the new technology has to prove that its reliability is at least as good - if not superior - as that of the conventional systems. Such superconducting cables must withstand probable pressure variations as well as some electrical overstressing. In the context of this paper, some aspects of the electrical insulation for superconducting applications will be mentioned and analyzed. Moreover, some proposals for future research will be made.

\section{SOME GENERAL COMMENTS}

Electrical insulation is crucial to the good performance of very low temperature energy systems or for any energy system for that matter. Typical applications of superconducting systems are the superconducting faults current limiter (SFCL) and the superconducting magnetic energy storage system (SMES). HTS transformers are also a possible alternative to conventional transformers since they reduce the losses by $60 \%$ or even more. They are more environment-friendly and they use liquid nitrogen instead of mineral oil as insulation and coolant. They are more reliable than the conventional transformers. Their possible applicability has been demonstrated in countries such as Japan, the USA, Germany, South Korea and New Zealand [3]. HTS cables have been built in the past few decades. Such cables use as insulation either non-polar polymer films with liquid helium or nitrogen, or polymer films such as cross-linked polyethylene XLPE. In the case of underground cables, insulating materials that have been used for conventional applications, have been adapted to HTS applications. Consequently, materials such as polypropylene laminated paper (PPLP) [4], ethylene propylene rubber (EPR), XLPE, low-density polyethylene (LDPE) and PTFE have been investigated accordingly [4-6]. However, with the requirements for higher voltages (e.g. $275 \mathrm{kV}$ ), superconducting cables had considerable dielectric losses [7]. In such voltages, in order to reduce dielectric losses, other insulating materials were used (e.g. Tyvek - a polyethylene nonwoven fabric - as opposed to conventional PPLP, or the ultra high molecular weight polyethylene (UHMWPE)) [8-10].

\section{ON SUPERCONDUCTIVITY}

Superconductors transfer practically current with zero losses when their temperature falls below a certain value, which is called "critical temperature". Superconductors preserve their properties in a region which is defined by three quantities, namely the critical current density Jc, the critical temperature $\mathrm{Tc}$ (the temperature at which the resistance becomes zero) and the critical magnetic field $\mathrm{Hc}$ (as the magnetic field increases the superconductivity of the material is 
reduced). The higher the values of all three aforementioned quantities, the easier becomes the application of the superconductors. Increase of one of the aforementioned quantities may return the material to its previous (nonsuperconducting) state. When a superconductor loses its superconducting state, it needs a considerable amount of time in order to revert to superconduction, whereas when a superconductor has an excessive current, the consequences may be deleterious because of the released heat [11, 12]. HTS superconductors are more efficient than common superconductors which function at lower critical temperature. HTS superconductors are in superconducting state at temperatures higher than $77 \mathrm{~K}$ in applications with weak magnetic fields. On the contrary, materials of lower critical temperatures, such as $\mathrm{Nb}-\mathrm{Ti}$ and $\mathrm{Nb}_{3} \mathrm{Sn}$, must be cooled at $4 \mathrm{~K}$ in order to have superconducting properties. However, in this way, their cost rises [13].

Regarding high voltage cables, there are two main categories of cables, the cables of warm dielectric (WD) and the cables of cold dielectric (CD). Cables of WD have liquid nitrogen whereas the solid insulation can be at room temperature. Their insulation can be XLPE, PPLP or ethylene propylene rubber (EPR). The insulation is applied on the outer wall of the cryostat. This type of cables presents higher losses, which in turn cause higher released amounts of heat [14]. In the $\mathrm{CD}$ cables, the insulating material is on the inner wall of the cryostat. In this case, the liquid nitrogen functions both as coolant and as dielectric. This type of cables has an increased cost but, on the other hand, has lower losses and a higher conduction in higher currents $[13,15]$. In the Triax cables, all three phases are in a single cable. Such a construction reduces the electric losses and requires half of the superconducting material compared with the CD cables. Triax cables occupy less space than the aforementioned WD and CD cables [13].

\section{INSULATING MATERIALS FOR SUPERCONDUCTING} APPLICATIONS, PARTIAL DISCHARGES, AND ELECTRICAL TREES

As far as cables at very low temperatures are concerned, there are four types of insulations: 1) vacuum insulation with solid insulators, 2) liquid insulation with solid insulators, 3) tape insulation impregnated with liquid helium or liquid nitrogen, and 4) liquid helium with solid insulation $[4,16]$. It goes without saying that in the above cases, the solid insulation must be compatible with the liquid or the vacuum, that the thermal expansion or contraction must be within certain limits and that the cost of construction must be reasonable [17]. Generally speaking, an insulation is affected by factors which tend to reduce its molecular structure, such as high temperatures (which influence the conductivity and the generation of partial discharges), mechanical stressing (which reduces the distance between the electrodes), affecting thus the breakdown strength [18]. Partial discharges are very dangerous in very low temperatures since they produce significant amounts of heat, leading in this way to the total failure of the insulation $[1,16]$. In the case of superconducting insulation, Partial Discharges (PD) may contribute to the increase of dielectric losses. A way to reduce such effects is to increase the pressure, preventing therefore the creation of bubbles. In this way, PD activity is reduced and the inception voltage increases.
PD measurements are considered crucial for cryogenic applications because PD are the main source of aging and breakdown of insulations in such low temperatures. Various techniques have been proposed in relation to such measurements. Phase-Resolved Partial Discharge (PRPD) measurements as well as the Current Pulse Waveform Analysis (CPWA) measurements have been proposed for a consequent study of PD in very low temperatures insulating systems. Whereas the first has the advantage of offering an overall picture of the state of the insulation, the latter method can obtain detailed individual PD currents pulses together with the time transition from PD inception to breakdown with the PD detection sensitivity of $0.1 \mathrm{pC}[4,19-22]$. It has to be noted that during the past few years, a new technique was developed [23]. The latter technique is named Chaotic Analysis of PD (CAPD) and is based on three normalized parameters obtained from two consecutive $\mathrm{PD}$ pulses, i.e. amplitude difference $\left(\mathrm{P}_{t}\right)$, occurring time difference $\left(T_{t}\right)$ and correlation between $P_{t}$ and $T_{t}$. Authors in [23] claim that besides PRPD, their proposed method is suitable for HTS applications.

Electrical treeing in polymers at cryogenic temperatures may also be noted. Electrical trees may be the result of PD and/or some mechanical stressing. Inception voltages for treeing are in general higher than the inception voltages at room temperature, and even if the electrical trees start, their development is much slower [17, 24]. In [24], a significant point is made, namely that, if a polymer is defect-free, it contracts heavily at very low temperatures and - inadvertently introduced - voids are squeezed out. However, if PD occur in a void at cryogenic temperatures, deterioration may proceed more rapidly and malignantly than in the case encountered at room temperature.

\section{HTS INSULATION}

Insulation is crucial to the successful performance of supeconducting apparatus [25]. The characteristics of liquid nitrogen $\left(\mathrm{LN}_{2}\right)$ are fundamental to many HTS applications. Moreover, the role of composite insulating systems (from $\mathrm{LN}_{2}$ and solid insulating materials, such as paper and epoxy) is also very important, as well as the gaseous nitrogen $\left(\mathrm{GN}_{2}\right)$ and the vacuum [21]. For the correct, reliable and practical design of an HTS insulation is necessary to examine factors that are crucial for the cryogenic liquids, such as the state of the electrode surfaces, and their effect on the breakdown strength [26]. As critical factors influencing the PD behavior and the breakdown strength of $\mathrm{LN}_{2}$ are the quality of electrode surfaces, the volume of insulation, the presence of bubbles and foreign matter $[27,28]$.

\section{INFUENCE OF ELECTRODE SURFACE, STRESSED VOLUME AND BUBBLES}

It is well known that the breakdown strength of conventional insulating materials is affected by the electrode surface (quality of the surface as well as size of the electrodes) and the stressed volume [29, 30]. Relatively recently, it was shown that the breakdown strength decreases with the increase of the gap spacing and the electrode area for sub-cooled nitrogen $\left(\mathrm{SLN}_{2}\right)$. Such phenomena were observed because the amount of impurities and bubbles increases with the gap 
spacing and the electrode diameter [31]. In the same publication, it was reported that the number and size of bubbles as the weak points to cause breakdown can be reduced by high pressures in $\mathrm{SLN}_{2}$. Similarly the low temperatures contribute to reduce the number and size of bubbles. The question as to whether the size effect is due more to the electrode area or to the stressed volume in $\mathrm{SLN}_{2}$, was treated in [21, 32]. Experimental results revealed that the breakdown mechanism changed from an area dominant to volume effective region at larger electrode configurations in $\mathrm{SLN}_{2}$ [32]. Such behavior was also noted in conventional insulating liquids [29, 30, 33, $34]$, i.e. that the influence of the stressed volume is more crucial with larger electrodes.

In the presence of bubbles, breakdown strength is reduced. In such a case, the breakdown voltage depends on the bubble volume. Relatively recent research indicated the dependence of the breakdown strength of $\mathrm{SLN}_{2}$ on the bubble presence. On the other hand, in such a case, an increase of pressure may have a beneficial effect on the breakdown strength since higher pressures suppress vapor bridge formation avoiding thus a precipitous drop in breakdown strength [35]. Bubbles represent the weak link in $\mathrm{SLN}_{2}$ since the discharge activity starts from them. In fact, Paschen's law is also valid at cryogenic temperatures making thus easier the calculation of inception voltages [36, 37]. Furthermore, as was reported in [38], the development of discharges in bubbles is a process of ionizations and hence an increase in pressure affects the quantity of micro-bubbles. Increasing pressure and reducing temperature may therefore offer an effective means to reduce the probability of inception of pre-breakdown streamer activity since the aforementioned quantities may influence streamer behavior and thus reduce the number of PD events from an anode tip [38]. Reducing temperature has as a result the condensation of existing bubbles, which in turn leads to a decrease of the electrically weak links [39]. A sudden increase of temperature may cause - in combination with the electric stress - the so-called bubble disturbance. The latter may reduce the voltage breakdown from $165 \mathrm{kV}_{\text {peak }}$ to $80 \mathrm{kV}_{\text {peak }}$ for a gap spacing of $8 \mathrm{~mm}$ with a sphere-plane electrode arrangement [31, 40].

\section{INFUENCE OF UNIFORM AND NON-UNIFORM ELECTRIC FIELDS}

The applied electric field has a preponderant role in determining the breakdown strength of insulating materials and/or of the insulation in electrical apparatus [16]. Insulating materials at very low temperatures could not be an exception to the rule. Earlier work indicated that the breakdown voltage of liquid helium $(\mathrm{He})$ and liquid nitrogen $\left(\mathrm{LN}_{2}\right)$ is higher with uniform fields than with non-uniform fields [27]. The initial increase of breakdown voltage with the gap spacing for both the aforementioned liquids, even with a point-plane electrode arrangement, and the subsequent leveling-off may be due to the low latent heat of cryogenic liquids, which may lead to the creation of vapor around the point electrode [27]. Similar data to [27] were collected in [41], where authors observed that the impulse breakdown voltage is higher than the $\mathrm{AC}$ breakdown voltage for both sphere-plane and point-plane electrodes, with the former giving a much more distinct difference than the latter. Agreeing qualitatively with [27], the leveling-off of the breakdown voltage with increasing the gap spacing - in a sphere-plane arrangement - was also reported in [42], where the leveling-off was interpreted with the stabilization of the maximum electric field at larger gaps. The importance of bubbles on breakdown strength with various electrode arrangements was pointed out in [42]. More generated bubbles lower significantly the AC breakdown strength with both sphere-sphere and with tape electrodes, their effect being more emphatic with the latter [42]. The applied electric field has a vital influence on streamer propagation. Streamer propagation is to a significant extent determined by the macroscopic electric field $[17,27]$. Experimenting with sphere-plane electrodes and with pressures of $500 \mathrm{kPa}$, it was shown that positive streamers have a higher velocity than negative streamers and thus, positive streamers result in lower breakdown strength [17, 27]. Such data were confirmed in yet another publication, where it was indicated that a transition from slow to fast positive streamer was observed at a threshold voltage below the breakdown voltage [43]. In [43], it was pointed out that at very low temperatures, with sphere-plane electrodes, and with impulse voltages there is a remarkable polarity effect [44], namely that at positive polarity a faster streamer was noticed whereas with negative polarity the phenomenon was slower. In this respect there is agreement between [45] and [17, 27].

\section{ON THE DEGRADATION OF COMPOSITE INSULATING SYSTEMS}

PD consist one of the major sources of degradation of insulating materials [46, 47]. In an non-uniform electrode system containing a disc of PTFE in $\mathrm{LN}_{2}$, an increase of the applied voltage led to an increase of the cumulative number of $\mathrm{PD}$ as well as of their maximum values [38]. An increase of pressure in such an insulating system from $100 \mathrm{kPa}$ to $400 \mathrm{kPa}$, reduces the $\mathrm{PD}$ number, whereas a reduction of temperature does not have any remarkable effect on the slow negative streamers. On the contrary, a reduction in temperature causes a reduction of the fast positive streamers [38]. Further studies regarding the effect of pressure on the inception stress of a composite insulating system consisting of $\mathrm{LN}_{2} /$ polypropylene, indicated a decrease of inception stress by about $13 \%-40 \%$ when the pressure was reduced from $200 \mathrm{kPa}$ to $100 \mathrm{kPa}$ [48]. In a system consisting of $\mathrm{LN}_{2} /$ polypropylene laminated paper (PPLP) with butt gaps, it was noted that the inception stress depended on the butt gap thickness and that thicker butt gaps resulted in a larger inception stress drop. This is probably due to the existing probability of weak points of the electrical insulation at butt gaps [49]. Regarding the role of butt gaps and their related parameters, there is a striking similarity between the observations of the above publication and those reported using conventional insulating systems $[50,51]$, i.e. that the butt gaps - if not well impregnated - may be the weak point of a composite insulation. PD current pulses recorded at pressures of $0.1 \mathrm{MPa}, 0.12 \mathrm{MPa}, 0.15 \mathrm{MPa}$, and $0.2 \mathrm{MPa}$, confirmed - in a more recent publication - the above observations, namely that with increasing pressure, the PD current pulses become smaller and smaller [21].

Solid insulators are used in combination with $\mathrm{LN}_{2}$ for some HTS applications. Various solid insulating materials have been 
tried, such as PPLP, Tyvek, Nomex, Kapton, PVA, PMMA, PVB and PA66. The breakdown strength of PPLP, Kapton and PA66 was shown to be superior to the breakdown strength of other materials [52]. In yet another study by the same group of authors, it was indicated that the breakdown strength of Kapton/ $/ \mathrm{LN}_{2}, \quad$ polycarbonate/ $\mathrm{LN}_{2}, \quad \mathrm{G} 10 / \mathrm{LN}_{2} \quad$ (G10 being fiberglass reinforced plastic) and polyetherimide $/ \mathrm{LN}_{2}$ depends on the frequency, and it indeed decreases with frequency [53]. Such a decrease is possibly due to the dissipation of space charge in the dielectric. According to earlier works, charge dissipation from charge traps depends on the frequency of the applied voltage leading to reduced partial discharge at low frequency $[54,55]$. The properties of solid insulation at very low temperatures depend also on the additives as well as on the particular experimental conditions. For example, the HDPE presents a small increase of $\tan \delta$ at $4.2 \mathrm{~K}$ in comparison with the $\tan \delta$ at $77 \mathrm{~K}$. Mechanical properties, such as the modulus of elasticity, are also most important since a combination of electrical and mechanical stresses may cause cracks [56-60].

\section{DISCUSSION AND PROPOSALS FOR FUTURE RESDEARCH}

Regarding HTS applications, it can be said that liquid nitrogen is an excellent medium for high voltage apparatus. It acts as both insulating and cooling medium for many HTS applications. It also has the advantage of low cost. It is chemically inert and thus the risk of fire is considerably reduced. One of the problems facing the HTS cables is that they must have high currents in order to have beneficial economic advantages for the companies and the end users. In the case of interruption of the superconducting state there may be a sudden failure, the latter may provoke a chain reaction which in turn may cause a generalized instability of the whole network. In such a case, the temperature of the cable may increase dramatically. That may have as a consequence that a considerable time interval will be required in order for the cable to reach its usual superconducting state. The remedy of a larger number of lapped tapes is not feasible since that would require increasing costs. Consequently, the possible solution will be in improving the materials of such a cable. Improved HTS cable designs based on YBCO as well as a reduction of the cost of cooling systems are proposed [61, 62]. During the last decade, the cost of superconducting materials has been reduced by about $10 \%$ per annum [62] and it is hoped that this trend will continue. Furthermore - although the cost of a superconducting apparatus is still high in comparison with the cost of a conventional apparatus - a factor that has to be taken into account is that much lesser space is required to accommodate superconducting equipment $[63,64]$.

With respect to materials research, further work has to be performed regarding the surface discharges in $\mathrm{LN}_{2}$ /polymeric insulation uniform electrode arrangements [65]. Moreover, very low frequency (VLF) measurements regarding the insulation at cryogenic temperatures may offer an effective diagnostic technique to assess early insulation degradation [6668]. Partial discharges due to defects must be further explored with insulating systems at very low temperatures both w.r.t their mechanisms and classification, as was done with conventional polymers at normal temperature with isolated as well as multiple defects $[69,70]$. It is needless to say that with the advent of polymer nanocomposites, a new prospect opens in the field of the applications at very low temperatures [7174]. Research in this direction has already been performed and the prospects of employing polymer nanocomposites has been discussed, although one gets the impression that more effort was put into clarifying their mechanical properties rather than their electrical properties [75-78]. Also more effort has to be made regarding the expected life time of insulating materials (and insulating systems) at very low temperatures, especially in the view of earlier works on electrical stressing of HTS lapped tape insulated model cables [79].

\section{Conclusions}

In the present paper, a short review is offered regarding some aspects of insulating materials at very low temperatures. Some factors affecting the dielectric behavior of these materials are discussed. Although the very low temperature technology presents certain advantages compared to conventional technologies, more work has to be done w.r.t. the improvement of materials at such temperatures and the economic feasibility of such endeavors.

\section{REFERENCES}

[1] R. D. B. Ouboter, "Heike Kamerlingh Onnes's discovery of superconductivity", Scientific American, Vol. 276, No. 3, pp. 98-103, 1997

[2] J. G. Bednorz, K. A. Muller, "Possible high $T_{c}$ superconductivity in the Ba-La-Cu-O system", Zeitschrift Fuer Physik B-Condensed Matter, Vol. 64, No. 2, pp. 189-193, 1986

[3] Working Group D1.38, Common characteristics and emerging test techniques for high temperature superconducting power equipment, Cigre, 2015

[4] F. Krahenbuhl, B. Bernstein, M. Danikas, J. Densley, K. Kadotani, M. Kahle, M. Kosaki, H. Mitsui, M. Nagao, J. Smit, T. Tanaka, "Properties of electrical insulating materials at cryogenic temperatures: A literature review", IEEE Electrical Insulation Magazine, Vol. 10, No. 4, pp. 10-22, 1994

[5] M. Kosaki, "Research and development of electrical insulation of superconducting cables by extruded polymers", IEEE Electrical Insulation Magazine, Vol. 12, No. 5, pp. 17-24, 1996

[6] A. Bulinski, J. Densley, "High voltage insulation for power cables utilizing high temperature superconductivity", IEEE Electrical Insulation Magazine, Vol. 15, No. 2, pp. 14-22, 1999

[7] M. Yagi, J. Liu, S. Mukoyama, T. Mitsuhashi, J. Teng, N. Hayakawa, X. Wang, A. Ishiyama, N. Amemiya, T. Hasegawa, T. Saitoh, O. Maruyama, T. Ohkuma, "Experimental results of 275-kV 3-kA rebco HTS power cable", IEEE Transactions on Applied Superconductivity, Vol. 25, No. 3, Article ID 5401405, 2015

[8] N. Hayakawa, "Introduction of Cigre WG D1.64 and topics on insulation issues on superconducting cables and fault current limiters", $12^{\text {th }}$ IEEE International Conference on the Properties and Applications of Dielectric Materials, Xi'an, China, May 20-24, 2018

[9] W. Weihan, H. Fengnian, "Mechanical and dielectric assessment of ultrahigh molecular weight polyethylene insulation for cryogenic applications", IEEE Transactions on Electrical Insulation, Vol. 27, No. 3, pp. 504-512, 1992

[10] W. Gao, D. Ding, Q. Yin, "Influences of aggregative state on electrical trees growth characteristics under cryogenic condition", 9th International Conference on the Properties and Applications of Dielectric Materials, Harbin, China, July 19-23, 2009

[11] G. Papadopoulos, Thermal analysis of superconducting cables with the use of finite volume and finite element methods, BSc Thesis, Aristotle University of Thessaloniki,, 2017 (in Greek) 
[12] M. Nassi, "HTS prototype for power transmission cables: Recent results and future programs", Superconductor Science and Technology,Vol. 13, No. 5, pp. 460-463, 1999

[13] P. Katsiroubas, Theory of superconductivity and applications of superconducting materials in power applications, BSc Thesis, National Technical University of Athens, 2014 (in Greek)

[14] M. Nassi, High temperature superconducting (HTS) cable systems, CIGRE, 2003

[15] C. Farmakas, "Power applications with superconducting materials of high Temperature", BSc Thesis, Aristotle University of Thessaloniki, 2003 (in Greek)

[16] T. J. Gallagher, A. J. Pearmain, High voltage measurement, testing and design, John Wiley and Sons, 1984

[17] J. Gerhold, "Properties of cryogenic insulants", Cryogenics, Vol. 38, No. 11, pp. 1063-1081, 1998

[18] M. S. Naidu, V. Kamaraju, High voltage engineering, McGraw-Hill, 1995

[19] A. Kelen, M. G. Danikas, "Evidence and presumption in PD diagnostics", IEEE Transactions on Dielectrics and Electrical Insulation, Vol. 2, No. 5, pp. 780-795, 1995

[20] E. Gulski, "Digital analysis of partial discharges", IEEE Transactions on Dielectrics and Electrical Insulation, Vol. 2, No. 5, pp. 822-837, 1995

[21] H. Okubo, M. Noe, J. Cho, A. Malozemoff, L. Martini, S. Nagaya, F. Schmidt, C. Sumereder, P. Tixador, B. Wacker, A. Wolsky, "Status of development and field test experience with high-temperature supeconducting power equipment", Electra, Vol. 250, pp. 61-63, 2010

[22] H. Okubo, N. Hayakawa, "A novel technique for partial discharge and breakdown investigation based on current pulse waveform analysis", IEEE Transactions on Dielectrics and Electrical Insulation, Vol. 12, No. 4, pp. 736-744, 2005

[23] I. J. Seo, Y. J. Lee, J. K. Seong, W. J. Shin, B. W. Lee, J. Y. Koo, "Identification and insulation defects in cryogenic dielectric materials for the HTS power applications", IEEE Transactions on Applied Superconductivity, Vol. 22, No. 3, Article ID 7701304, 2012

[24] M. Kosaki, M. Nagao, N. Shimizu, Y. Mizuno, "Solid insulation and its deterioration", Cryogenics, Vol. 38, No. 11, pp. 1095-1104, 1998

[25] J. I. Heo, J. Hong, S. Nam, S. Choi, H. Kang, "Design of current leads for a high voltage superconducting apparatus", IEEE Transactions on Applied Superconductivity, Vol. 23, No. 3, Article ID 4800805, 2013

[26] N. Hayakawa, H. Kojima, M. Hanai, H. Okubo, "Recent progress in electrical insulation techniques for HTS power apparatus", Physics Procedia, Vol. 36, pp. 1305-1308, 2012

[27] J. Gerhold, "Potential of cryogenic liquids for future power equipment insulation in the medium high voltage range", IEEE Transactions on Dielectrics and Electrical Insulation, Vol. 9, No. 6, pp. 878-890, 2002

[28] J. Gerhold, "Cryogenic liquids-A prospective insulation basis for future power equipment", IEEE Transactions on Dielectrics and Electrical Insulation, Vol. 9, No. 1, pp. 68-75, 2002

[29] M. Danikas, Factors affecting the breakdown strength of transformer oil, MSc Thesis, University of Newcastle upon Tyne, 1982

[30] M. G. Danikas, "Breakdown of transformer oil", IEEE Electrical Insulation Magazine, Vol. 6, No. 5, pp. 27-34, 1990

[31] N. Hayakawa, S. Nishimachi, T. Mastuoka, H. Kojima, M. Hanai, H. Okubo, "Breakdown characteristics and size effect in sub-cooled liquid nitrogen", 18th International Conference on Dielectric Liquids, Bled, Slovenia, June 29-July 3, 2014

[32] N. Hayakawa, H. Sakakibara, H. Goshima, M. Hikita, H. Okubo, "Breakdown mechanism of liquid nitrogen viewed from area and volume effects", IEEE Transactions on Dielectrics and Electrical Insulation, Vol. 4, No. 1, pp. 127-134, 1997

[33] W. R. Bell, "Influence of size on the dielectric strength of transformer oil", IEEE Transactions on Electrical Insulation, Vol. 12, No. 4, pp. 281292, 1977

[34] B. Salvage, "The dielectric breakdown of some simple organic liquids", Proceedings of the IEE-Part IV: Institution Monographs, Vol. 98, No. 1, pp. 15-22, 1951
[35] I. Sauers, R. James, A. Ellis, E. Tuncer, G. Polizos, M. Pace, "Effect of bubbles on liquid nitrogen in plane-plane electrode geometry from 100$250 \mathrm{kPa}$ ", IEEE Transactions on Applied Superconductivity, Vol. 21, No. 3, pp. 1892-1895, 2011

[36] M. Blaz, M. Kurrat, "Discharge mechanisms in liquid nitrogen with thermally induced gas bubbles", Journal of Physics: Conference Series Vol. 507, Article ID 032006, 2014

[37] T. P. Hong, P. E. Frayssines, O. Lesaint, F. Aitken, F. Devaux, "Influence of vapor bubbles initiated by steady heating on the breakdown of liquid nitrogen", Annual Report Conference on Electrical Insulation and Dielectric Phenomena, Albuquerque, USA, October 1922, 2003

[38] D. J. Swaffield, P. L. Lewin, G. Chen, S. G. Swingler, "Partial discharge characterization of streamers in liquid nitrogen under applied AC voltages", IEEE Transactions on Dielectrics and Electrical Insulation, Vol. 15, No. 3, pp. 635-646, 2008

[39] S. Nishimachi, N. Hayakawa, H. Kojima, M. Hanai, H. Okubo, "Pressure and temperature dependence of breakdown characteristics of sub-cooled liquid nitrogen", Annual Report Conference on Electrical Insulation and Dielectric Phenomena, Montreal, Canada, October 14-17, 2012

[40] S. Fink, R. Mueller, M. Noe, V. Zwecker, H. R. Kim, "Withstand alternating voltage of liquid nitrogen in the presence of gas bubbles", 18th International Conference on Dielectric Liquids, Bled, Slovenia, June 29-July 3, 2014

[41] D. S. Kwag, H. G. Cheon, J. H. Choi, H. J. Kim, J. W. Cho, M. S. Yun, S. H. Kim, "The electrical insulation characteristics for a HTS cable termination", IEEE Transactions on Applied Superconductivity, Vol. 16, No. 2, pp. 1618-1621, 2006

[42] D. R. James, I. Sauers, A. R. Ellis, E. Tuncer, K. Tekletsadik, D. W. Hazelton, "Breakdown and partial discharge measurements of some commonly used dielectric materials in liquid nitrogen for HTS applications", IEEE Transactions on Applied Superconductivity, Vol. 17, No. 2, pp. 1513-1516, 2007

[43] S. Li, J. Sheng, Y. Chen, Z. Lin, Y. Yin, L. Yao, Z. Hong, "Bubble behavior and its influence on insulation properties of liquid nitrogen for superconducting power apparatus", IEEE Transactions on Applied Superconductivity, Vol. 23, No. 3, Article ID 5000205, 2013

[44] P. E. Frayssines, O. Lesaint, N. Bonifaci, A. Denat, S. Lelaidier, F. Devaux, "Prebreakdown phenomena at high voltage in liquid nitrogen and comparison with mineral oil", IEEE Transactions on Dielectrics and Electrical Insulation, Vol. 9, No. 6, pp. 899-909, 2002

[45] P. E. Frayssines, N. Bonifaci, A. Denat, O. Lesaint, "Steamers in liquid nitrogen: Characteristics and spectroscopic determination of gaseous filament temperature and electron density", Journal of Physics D: Applied Physics, Vol. 35, No. 4, pp. 369-377, 2002

[46] J. C. Devins, "The physics of partial discharges in solid dielectrics", Conference on Electrical Insulation \& Dielectric Phenomena-Annual Report, Claymont, USA, October 21-25, 1984

[47] A. Eigner, K. Rethmeier, "An overview on the current status of partial discharge measurements on AC high voltage cable accessories", IEEE Electrical Insulation Magazine, Vol. 32, No. 2, pp. 48-55, 2016

[48] N. Hayakawa, M. Nagino, H. Kojima, M. Goto, T. Takahashi, K. Yasuda, H. Okubo, "Dielectric characteristics of HTS cables based on partial discharge measurement", IEEE Transactions on Applied Superconductivity, Vol. 15, No. 2, pp. 1802-1805, 2005

[49] H. Okubo, M. Hazeyama, N. Hayakawa, S. Honjo, T. Masuda, "V-t characteristics of partial discharge inception in liquid nitrogen/ $\mathrm{PPLP} / \mathrm{sup} / \mathrm{spl} \mathrm{reg} / /$ composite insulation system for HTS cable", IEEE Transactions on Dielectrics and Electrical Insulation, Vol. 9, No. 6, pp. 945-951, 2002

[50] A. J. Pearmain, M. G. Danikas, "A study of the behavior of a uniaxially oriented polyethylene tape/oil insulating system subjected to electrical and thermal stresses", IEEE Transactions on Electrical Insulation, Vol. 22, No. 4, pp. 373-382, 1987

[51] M. G. Danikas, "Study of samples of a composite insulating system under electrical and thermal stresses", IEEE Electrical Insulation Magazine, Vol. 6, No. 1, pp. 18-23, 1990 
[52] E. Tuncer, G. Polizos, I. Sauers, D. R. James, A. R. Ellis, J. M. Messman, T. Aytug, "Polyamide 66 as a cryogenic dielectric", Cryogenics, Vol. 49, No. 9, pp. 463-468, 2009

[53] I. Sauers, E. Tuncer, G. Polizos, D. R. James, A. R. Ellis, M. O. Pace, "Very low frequency breakdown strengths of electrical insulation materials at cryogenic temperatures", IEEE Conference on Electrical Insulation and Dielectric Phenomena, Virginia Beach, USA, October 1821, 2009

[54] A. Cavallini, G. C. Montanari, "Effect of supply voltage frequency on testing of insulation system", IEEE Transactions on Dielectrics and Electrical Insulation, Vol. 13, No. 1, pp. 111-121, 2006

[55] C. Forssen, H. Edin, "Partial discharges in a cavity at variable applied frequency part 2: Measurements and modeling”, IEEE Transactions on Dielectrics and Electrical Insulation, Vol. 15, No. 6, pp. 1610-1616, 2008

[56] A. C. Muller, "Properties of plastic tapes for cryogenic power cable insulation", in: Nonmetallic Materials and Composites at Low Temperatures, Plenum Press, 1979

[57] E. B. Forsyth, A. J. McNemey, A. C. Muller, "Dielectric design xconsiderations for a flexible superconducting power transmission cable", Advances in Cryogenic Engineering, Vol. 22, pp. 296-305, 1977

[58] G. H. Morgan, A. C. Muller, "Bending behavior of lapped plastic EHV cables", IEEE International Conference on Electrical Insulation, Boston, USA, June 9-11, 1980

[59] P. G. Priaroggia, E. Occhini, N. Palmieri, "A brief review of the theory of paper lapping of a single core high voltage cable", Proceedings of IEE Part C: Monographs, Vol. 108, No. 13, pp. 25-34, 1961

[60] E. B. Forsyth, "The dielectric insulation of superconducting power cables", Proceedings of the IEEE, Vol. 79, No. 1, pp. 31-40, 1991

[61] V. Selvamanickam, J. Dackow, "Progress in superpower's 2G HTS wire development and manufacturing", DOE Advanced Cables \& Conductors Peer Review, Alexandria, USA, June 29-July 1, 2010

[62] M. Elsherif, P. Taylor, S. Blake, "Investigating the potential impact of superconducting distribution networks", 22nd International Conference and Exhibition on Electricity Distribution, Stockholm, Sweden, June 1013,2013

[63] W. Yuan, S. Venuturumilli, Z. Zhang, Y. Mavroconstanti, M. Zhang, "Economic feasibility study of using high-temperature superconducting cables in UK's electrical distribution networks", IEEE Transactions on Applied Superconductivity, Vol. 28, No. 4, Article ID 5401505, 2018

[64] P. McGuckin, G. Burt, "Overview and assessment of superconducting technologies for power grid applications", 53rd International Universities Power Engineering Conference, Glasgow, UK, September 4-7, 2018

[65] E. Tuncer, I. Sauers, D. R. James, A. R. Ellis, "Electrical insulation characteristics of glass fiber reinforced resins", IEEE Transactions on Applied Superconductivity, Vol. 19, No. 3, pp. 2359-2362, 2009

[66] E. Gockenbach, W. Hauschild, "The selection of the frequency range for high-voltage on-site testing of extruded insulation cable systems", IEEE Electrical Insulation Magazine, Vol. 16, No. 6, pp. 11-16, 2000

[67] S. Morsalin, B. T. Phung, M. G. Danikas, "Influence of cavity geometry on partial discharge measurement at very low frequency", IEEE Electrical Insulation Conference, Calgary, Canada, June 16-19, 2019

[68] S. Morsalin, B. T. Phung, M. G. Danikas, D. Mawad, "Diagnostic challenges in dielectric loss assessment and interpretation: A review", IET Science, Measurement \& Technology, Vol. 13, No. 6, pp. 767-782, 2019

[69] H. A. Illias, M. A. Tunio, A. H. A. Bakar, H. Mokhlis, G. Chen, "Partial discharge phenomena within an artificial void in cable insulation geometry: Experimental validation and simulation", IEEE Transactions on Dielectrics and Electrical Insulation, Vol. 23, No. 1, pp. 451-459, 2016

[70] H. Illias, G. Altamimi, N. Mokhtar, H. Arof, "Classification of multiple partial discharge sources in dielectric insulation material using Cepstrum analysis-Artificial neural netweork", IEEJ Transactions on Electrical and Electronic Engineering, Vol. 12, No. 3, pp. 357-364, 2017
[71] C. W. Reed, "Polymer nanodielectrics-Basic concepts", IEEE Electrical Insulation Magazine, Vol. 29, No. 6, pp. 12-15, 2013

[72] E. David, M. Frechette, "Polymer nanocomposites-Major conclusions and acievements reached so far", IEEE Electrical Insulation Magazine, Vol. 29, No. 6, pp. 29-36, 2013

[73] M. G. Danikas, A. Bairaktari, R. Sarathi, A. B. B. A. Ghani, "A review of two nanocomposite insulating materials models: Lewis' contribution in the development of the models, their differences, their similarities and future challenges", Engineering, Technology \& Applied Science Research, Vol. 4, No. 3, pp. 636-643, 2014

[74] G. Melissinos, M. G. Danikas, "On polymer nanocomposites: Electrical treeing, breakdown models and related simulations", Engineering, Technology \& Applied Science Research, Vol. 8, No. 2, pp. 2627-2632, 2018

[75] E. Tuncer, I. Sauers, "Industrial applications perspective of nanodielectrics", in: Dielectric Polymer Nanocomposites, Springer, 2010

[76] N. Soleimani, S. M. Khalili, R. E. Farsani, Z. Hedayatnasab, "Mechanical properties of nanoclay reinforced polypropylene composites at cryogenic temperature", Journal of Reinforced Plastics and Composites, Vol. 31, No. 14, pp. 967-976, 2012

[77] N. Manoharan, V. Selvakumar, "Cryogenic mechanical properties of PP/MMT polymer nanocomposites", Indian Journal of Science and Technology, Vol. 7, No. S7, pp. 16-23, 2014

[78] S. Fu, Z. Sun, P. Huang, Y. Li, N. Hu, "Some basic aspects of polymer nanocomposites: A critical review”, Nano Materials Science, Vol. 1, No. 1, pp. 2-30, 2019

[79] M. O. Pace, I. Sauers, D. R. James, A. R. Ellis, "Aging of lapped tape insulated model cables at cryogenic temperature", Annual Report Conference on Electrical Insulation and Dielectric Phenomena, Cancun, Mexico, October 20-24, 2002 